\title{
Conceptualizing emotions along the dimensions of valence, arousal, and communicative frequency - implications for social-cognitive tests and training tools
}

\author{
Robert Hepach ${ }^{1,2}$ *, Dorit Kliemann ${ }^{1,3,4}$, Sebastian Grüneisen ${ }^{1}$, Hauke R. Heekeren ${ }^{1,3,4}$ and Isabel Dziobek ${ }^{1,3,4}$ * \\ ${ }^{1}$ Max Planck Research Group "Neurocognition of Decision Making," Max Planck Institute for Human Development, Berlin, Germany \\ ${ }^{2}$ Department of Developmental and Comparative Psychology, Max Planck Institute for Evolutionary Anthropology, Leipzig, Germany \\ ${ }^{3}$ Cluster of Excellence "Languages of Emotion," Freie Universität Berlin, Berlin, Germany \\ ${ }^{4}$ Department of Education and Psychology, Freie Universität Berlin, Berlin, Germany
}

Edited by:

Marina A. Pavlova, Eberhard Karls University of Tübingen, Germany

Reviewed by:

Olivier Piguet, Neuroscience

Research Australia, Australia

Georg Groen, University of UIm,

Germany

*Correspondence:

Robert Hepach, Department of

Developmental and Comparative

Psychology, Max Planck Institute for

Evolutionary Anthropology, Deutscher

Platz 6, 04103 Leipzig, Germany.

e-mail: hepach@eva.mpg.de;

Isabel Dziobek, Understanding

Interaffectivity, Cluster of Excellence

"Languages of Emotion," Freie

Universität Berlin, Habelschwerdter

Allee 45, 14195 Berlin, Germany.

e-mail: isabel.dziobek@fu-berlin.de

\begin{abstract}
Background and Objectives: Emotion words are mostly characterized along the classic dimensions of arousal and valence. In the current study we sought to complement this characterization by investigating the frequency of emotions in human everyday communication, which may be crucial information for designing new diagnostic or intervention tools to test and improve emotion recognition. Methods: One hundred healthy German individuals were asked to indicate the valence and arousal of 62 emotion words in a questionnaire. Importantly, participants were additionally asked to indicate the frequency with which they experience each emotion themselves and observe it in others. Results: Positive emotions were judged to occur more often than negative emotions in everyday life. The more negatively valenced emotions were rated to be observed more often in others than experienced in one-self. On the other hand more positively valenced emotions were experienced more often in one-self than they were observed in others. Finally, increasing age was associated with a decrease in the frequency of observing an emotion in other people. Limitations: Future studies with larger sample sizes are needed to ascertain if the findings also apply to other cultural and language contexts. Conclusion: These results imply a greater frequency of positive emotions than negative emotions in everyday communication. The finding of such a bias toward positive emotions can guide the selection of emotion words for implementation in socio-emotional intervention tools. Such a selection may represent an effective means for improving social-cognitive functioning in people with respective impairments.
\end{abstract}

Keywords: emotion, negativity bias, arousal, valence, communicative frequency

\section{INTRODUCTION}

Emotion recognition includes the capacity to read and interpret other people's emotions to successfully engage in social interactions. Many psychiatric disorders (such as autism spectrum conditions, borderline personality disorder, or schizophrenia) share severe impairments in successfully recognizing emotions and appropriately attributing mental states to others (Hobson et al., 1988; American Psychiatric Association, 1994; Baron-Cohen, 1995; Preißler et al., 2010; Montag et al., 2011; Ritter et al., 2011). There are a number of diagnostic tests and training tools (see, e.g., Baron-Cohen et al., 2001, 2004, 2007; Bölte et al., 2002; Dziobek et al., 2006), developed to identify emotion recognition deficits and to achieve improvement in those abilities. Recent tools were designed with an emphasis on using naturalistic stimuli as means of increasing task sensitivity (Baron-Cohen et al., 2001; Dziobek et al., 2006). To test or train an ecologically valid range of emotions, however, the question arises which emotions should be considered in designing new test or training tools.
There is a long tradition in emotion research to categorize emotions along several dimensions, such as arousal and valence (Russell, 1980; Russell and Barrett, 1999), showing that there is a bias along the negative valence of emotion words. This negativity bias describes an ontogenetically early rooted tendency of humans to attend more readily to negative than to positive emotions (Dunn, 1988; Peeters and Czapinski, 1990; de Haan et al., 2004; see Vaish et al., 2008, for a review). On the one hand, this is manifest in the more numerous occurrences of negative emotion words in the affective lexicon (Averill, 1980). On the other hand, positive emotions, such as joy and love, play distinctive roles in guiding human social behavior (Fredrickson, 1998) and are associated with life-enhancing effects (Cohn et al., 2009). Furthermore, the evolutionary importance of positive emotions, such as empathy and sympathy, has been pointed out by their effect in establishing social bonds and sustaining care-taking behavior (Darwin, 2004; Keltner, 2009; see, Goetz et al., 2010, for a review). 
The significance of both negative and positive tendencies in emotion words thus necessitates researchers to carefully consider these aspects when designing new tools aimed at enhancing emotion recognition capabilities. Interestingly, previous studies have not been specific when describing the selection criteria for emotions included in diagnostic or intervention tools. Baron-Cohen et al. (2001) introduced the "Reading the Mind in the Eyes Test," in which only the eye region of an emotional face is shown to identify the expression. This test includes 36 "target mental states," such as terrified, joking, and apologetic, without giving a reason for selecting these specific emotions. Similarly, Dziobek et al. (2006) introduced the "Movie for the Assessment of Social Cognition" (MASC), which includes a variety of emotions, such as jealousy, fear, anger, affection, embarrassment, and disgust, without providing a rationale for the particular selection of these emotions. Two emotion training tools for the treatment of autism were introduced in "Mindreading" (Baron-Cohen et al., 2004) and "Transporters" (Baron-Cohen et al., 2007), including 412 and 15 emotions, respectively. While the first approach represents an effort to include as many emotions as possible, it remains unclear why the second approach chose those specific 15 emotions over others. Of note, the above-mentioned studies and tools are not an exhaustive list of examples. Nevertheless they are illustrative of the fact that in general no specific criteria are reported by which emotions are included in the sample.

Traditionally, emotion words are judged along the dimensions of valence and arousal, the dimensional concept of "valencearousal-space" (Russell, 1980). This concept has offered an intuitive and didactically valuable approach for categorizing emotion words (Bradley and Lang, 1994). However, the reliance on arousal and valence ratings in establishing emotion taxonomies has been criticized for lacking semantic differentiation between emotions with near-to-identical arousal and valence ratings but distinct meanings (Fontaine et al., 2007). A potential dimension for complementing a categorization of emotions based on arousal and valence could be the frequency, with which emotions occur in everyday social interactions. Such a dimension can be particularly informative for identifying those positive and negative emotions which individuals are most likely to encounter in everyday life, i.e., those that have a higher communicative frequency. To the best of our knowledge, only one study to date has investigated the frequency of emotions in everyday life (Scherer et al., 2004). In this study, the authors reported the results of a questionnaire, in which 1242 individuals were asked to recall and describe an event that caused an emotion on the previous day. While this study provide compelling insights into how likely participants are to experience an emotion themselves, it did not investigate how likely an emotion is encountered in others. Furthermore, the study focussed on a sub-sample of six emotion categories which were reported to be the most frequent (anger family, happiness family, anxiety, sadness, stress, despair).

In the current study, we sought to extend this approach by asking participants to indicate how often they felt an emotion themselves and how often they observed an emotion in others. Importantly, we significantly extended the number of emotion words presented to the participants. We aimed to obtain an objective measure of communicative frequency of emotions in everyday human interactions by using a questionnaire that surveyed 100 healthy participants to assess not only the valence and arousal levels but also the frequency of emotions on a sample of 62 emotion words. We hypothesized that positive emotions would be judged to occur more frequently than negative ones, based on their importance in everyday social communication. In accordance with work by Scherer et al. (2004), we suggested that the frequency with which emotions occur may be one criterion for identifying their social relevance.

\section{MATERIALS AND METHODS PARTICIPANTS AND RECRUITMENT}

Participants were randomly selected from databases of the Max Planck Institute for Human Development, Berlin, Germany, and through public flyers or announcements in the Berlin area. People listed in the database did not have a history of psychological or neurological conditions. Individuals received payment for their participation, and the study was approved by the ethics committee of the Max Planck Institute for Human Development. A total of 100 individuals participated ( 50 male, mean age $=37$ years, $\mathrm{SD}=12$ years). The questionnaire could be filled out at home and then submitted via email/mail or filled out at the institute. There were no time constraints when completing the questionnaire.

\section{PRE-SELECTION PROCESS}

To arrive at a manageable size of emotion words, we pre-selected a set of emotion words to be rated in the questionnaire. In a first step we conducted a literature review on published articles that had assessed emotion taxonomies which differed in reports regarding the number of categorized emotion words, ranging from less than 150 words (Shaver et al., 1987; Morgan and Heise, 1988) to more than 500 words (Clore et al., 1987; Storm and Storm, 1987) in the English language. In a second step, we included all words that appeared in at least two taxonomies on an initial list that was translated from the English to the German language. The online database hosted by the University of Leipzig, Germany (http://wortschatz-uni-leipzig.de) provides the frequency of single words in the German written language, as well as significant neighbors and synonyms of these words (Biemann et al., 2004). Every word is assigned to a frequency class (FC) according to its occurrence in German corpora data. The general reference point for all words is the masculine definite article "der" because it is the most frequently used word in the German language. For example, if the word "lonely" has an FC-value of 12, it appears $2^{12}$ times less frequently than the reference word "der" in German. This information was used to further exclude translated words when (1) the translated words were under a frequency of 17 or (2) the translation itself significantly changed the meaning. The frequency value of 17 led to a manageable number of words between 50 and 100 . Furthermore, the database was used to exclude the less frequently occurring word of two synonyms.

In addition, emotion words were excluded on a conceptual basis: An emotion word had to resemble a prototypical episode of an emotional experience reasonably independent of dispositional and situational constraints (Ben-Ze'ev, 1997; Rosenberg, 1998). We therefore excluded emotion words that were clearly situational, such as "homesick." Another important conceptual issue for excluding certain words was the potential for similarities between emotion words given that emotions can be grouped on 
a semantic basis. If two emotions shared the same "core affects" (Russell and Barrett, 1999) but differed in that one word is more specialized than the other, we only included the more general term (for instance, "angry" was included rather than "frantic" because the latter is a specialization of the former). A panel of five experts who each possessed a university degree in psychology agreed upon these conceptual exclusions. These methods resulted in a pre-selected sample of 62 emotion words.

\section{QUESTIONNAIRE DESIGN}

The 62 pre-selected emotions were further assessed in four different sections of a newly designed questionnaire. In the first two sections, participants rated each emotion with respect to arousal and valence by employing the visual analog scale, "self assessment manikin" (SAM, Bradley and Lang, 1994). This scale allowed participants to rate both the valence level ("very positive" to "very negative") and the arousal level ("very calming" to "very arousing") of an emotion using the nine-point Likert scale (Likert, 1932). The last two sections of the questionnaire measured the frequency with which each emotion occurred by employing two questions: (1) "How often do you feel the emotion yourself?" and (2) "How often do you observe this emotion in others?" The first measure represented the self-orientated communicative frequency rating (CF-self), while the second measure represented the other-orientated frequency rating (CF-other). For each emotion word, participants were instructed to indicate the frequency that the emotion either occurred or was observed on a Likert scale (1-9) with gaps in between each labeling word ("never" - “seldom” - “sometimes" - “often” - “always").

\section{RESULTS}

Table 1 summarizes the participants' demographic information including information about their educational levels based on the highest school degree obtained (see description in table caption). We additionally subdivided participants into three age groups (20-30, 31-40, and 41-50 years) to simplify data presentation.

\section{VALENCE AND AROUSAL RATINGS}

Based on the questionnaire ratings, each emotion was categorized as (1) being either high or low arousing and (2) having either negative (higher values) or positive valence, with a cut-off value of 5 (values smaller than 5 were considered "low" and values larger

Table 1 | Summary of participants' demographics $(N=100,50$ males $)$.

\begin{tabular}{llllr}
\hline & $\begin{array}{l}\text { Lower } \\
\text { education } \\
\text { level }\end{array}$ & $\begin{array}{l}\text { Intermediate } \\
\text { education } \\
\text { level }\end{array}$ & $\begin{array}{l}\text { Higher } \\
\text { education } \\
\text { level }\end{array}$ & Total \\
\hline 20-30 years & 8 & 14 & 19 & 41 \\
31-40 years & 2 & 12 & 7 & 21 \\
41-60 years & 10 & 16 & 12 & 38 \\
Total & 20 & 42 & 38 & 100
\end{tabular}

The education levels refer to participants highest school degree. The lower education is generally obtained after 9 years at school. Intermediate and higher level are generally obtained after 10 and 13 years, respectively. than 5 were considered "high"). There were more high arousing (43) than low arousing (19) emotion words, as well as more negative (38) than positive (24) emotion words (Fisher's Exact Test; $p<0.001)$. As predicted, the latter finding reflects the negativity bias in our sample. Table 2 shows the individual ratings for each of the 62 emotion words.

\section{COMMUNICATIVE FREQUENCY RATINGS}

We assessed how CF-self and CF-other scores related to one another using a Pearson's product-moment correlation. This analysis indicated that CF-self and CF-other were positively correlated $\left(r \_\right.$Pearson $=0.42, p<0.001$ ). Thus, ratings indicated that the more often an emotion is experienced in one-self, the more often it is observed in others.

In a subsequent analysis step, we investigated to what degree the frequency rating of an emotion was influenced by age, gender, education level, valence, and arousal ratings as well as the distinction between observing the emotion in one-self (self) and in others (other). We used a generalized linear mixed model (Baayen, 2008) with Poisson error distribution and log-link function including age, gender, education level, valence, arousal, and a dummy-coded self vs. other variable ( $0 \sim$ self, $1 \sim$ other $)$ as fixed effects and subject as well as emotion as random effects. The dependent measure was the frequency value for each emotion word. We fitted the model using the function "lmer" from the R-package lme4 (Bates and Maechler, 2009; R Development Core Team, 2009).

The full model provided a significantly better fit than the null model $\left(\chi^{2}=201.26, \mathrm{df}=6, p<0.001\right)$. Furthermore, an increase in valence, i.e., higher values resembling negative ratings, was associated with a decrease in frequency $(-0.03 \pm 0.003, z=-9.95$, $p<0.001)$. In addition, the frequency of an emotion was generally rated higher in others than in one-self $(0.05 \pm 0.008, z=6.26$, $p<0.001)$. There was no significant effect for age $(-0.002 \pm 0.001$, $z=-1.948, p=0.051)$, gender $(0.008 \pm 0.025, z=0.3, p=0.76)$, education level $(0.007 \pm 0.012, z=0.58, p=0.57)$, or arousal $(0.0002 \pm 0.002, z=0.064, p=0.95)$. Two highly significant main effects lead us to fit a second model including an interaction of the self/other factor and valence ( $z$-transformed) as an additional fixed effect. Fitting this model provided a better fit of the data compared to the null model $\left(\chi^{2}=470.42, \mathrm{df}=7\right.$, $p<0.001)$. Again, an increase in valence was associated with a decrease in frequency $(-0.14 \pm 0.008, z=-16.9, p<0.001)$. Likewise, the frequency of an emotion was generally rated higher in others than in one-self $(0.07 \pm 0.009, z=8.52, p<0.001)$. Again, there was no significant effect for age $(-0.002 \pm 0.001$, $z=-1.958, p=0.0502)$, gender $(0.008 \pm 0.025, z=0.3, p=0.75)$, education level $(0.007 \pm 0.012, z=0.55, p=0.58)$, or arousal $(0.0005 \pm 0.002, z=0.193, p=0.85)$. In addition, the interaction effect between valence and self/other was associated with the frequency rating $(0.14 \pm 0.008, z=16.39, p<0.001)$ suggesting that the effect of an emotion's valence on the frequency rating was dependent on whether the judgment was made for occurring in one-self or in others, respectively.

This led us to fit two additional models with age, gender, education level, valence, arousal, and a dummy-coded self vs. other variable $(0 \sim$ self, $1 \sim$ other $)$ as fixed effects and subject as well as emotion as random effects. One of the models used CF-self as 
Table 2 | Emotion ratings for arousal, valence, CF-self, CF-other, and CF-overall in alphabetical order.

\begin{tabular}{|c|c|c|c|c|c|}
\hline Emotion & Arousal & Valence & CF-self & CF-other & CF-overall \\
\hline Affectionate & 2.9 & 2.57 & 6.41 & 5.8 & 6.105 \\
\hline Aggressive & 8.12 & 7.67 & 4.26 & 5.9 & 5.08 \\
\hline Aggrieved & 5.91 & 5.65 & 4.85 & 5.05 & 4.95 \\
\hline Aghast & 7.2 & 6.47 & 3.71 & 4.43 & 4.07 \\
\hline Agonized & 6.99 & 7.52 & 2.42 & 3.21 & 2.815 \\
\hline Amused & 3.45 & 2.47 & 6.4 & 6.09 & 6.245 \\
\hline Angry & 8.06 & 7.5 & 4.58 & 5.38 & 4.98 \\
\hline Anxious & 7.04 & 6.59 & 4.07 & 5.2 & 4.635 \\
\hline Apologetic & 4.73 & 4.84 & 4.43 & 4.33 & 4.38 \\
\hline Ashamed & 5.88 & 6.01 & 3.56 & 3.8 & 3.68 \\
\hline Bored & 4.04 & 5.83 & 3.74 & 5.35 & 4.545 \\
\hline Carefree & 3.4 & 2.34 & 6.62 & 6.34 & 6.48 \\
\hline Caring & 3.65 & 3.06 & 6.53 & 5.48 & 6.005 \\
\hline Compassionate & 4.95 & 5.47 & 4.56 & 4.34 & 4.45 \\
\hline Concerned & 6.27 & 5.6 & 5.58 & 5.51 & 5.545 \\
\hline Confident & 2.7 & 2.61 & 6.55 & 5.52 & 6.035 \\
\hline Confused & 6.29 & 6.14 & 3.55 & 4.4 & 3.975 \\
\hline Contemptuous & 6.46 & 7.53 & 2.63 & 3.62 & 3.125 \\
\hline Content & 2.05 & 2.28 & 6.35 & 5.56 & 5.955 \\
\hline Cross & 6.97 & 6.68 & 5.22 & 6.11 & 5.665 \\
\hline Curious & 5.01 & 3.34 & 6.95 & 6.03 & 6.49 \\
\hline Desperate & 7.48 & 7.53 & 3.54 & 4.16 & 3.85 \\
\hline Disappointed & 5.95 & 6.73 & 4.72 & 5.26 & 4.99 \\
\hline Disgusted & 6.87 & 7.42 & 3.34 & 3.89 & 3.615 \\
\hline Doubtful & 6.05 & 6.25 & 4.85 & 5.45 & 5.15 \\
\hline Embarrassed & 4.96 & 5.04 & 4.19 & 4.73 & 4.46 \\
\hline Enthusiastic & 5.73 & 2.66 & 5.2 & 4.76 & 4.98 \\
\hline Envious & 7.54 & 6.75 & 3.89 & 5.09 & 4.49 \\
\hline Expectant & 5.37 & 3.57 & 5.49 & 5.88 & 5.685 \\
\hline Frantic & 8.41 & 7.41 & 3.27 & 3.5 & 3.385 \\
\hline Frustrated & 6.9 & 7.46 & 4.21 & 5.4 & 4.805 \\
\hline Grateful & 3 & 2.52 & 6.46 & 5.29 & 5.875 \\
\hline Grievous & 6.26 & 6.82 & 3.98 & 4.6 & 4.29 \\
\hline Guilty & 6.59 & 7.03 & 3.4 & 3.49 & 3.445 \\
\hline Hateful & 8.16 & 8.27 & 2.42 & 3.45 & 2.935 \\
\hline Humble & 4.96 & 5.9 & 3.48 & 3.25 & 3.365 \\
\hline Hurt & 6.26 & 6.64 & 3.88 & 4.76 & 4.32 \\
\hline In love & 6.27 & 1.72 & 5.48 & 5.52 & 5.5 \\
\hline Interested & 3.96 & 2.54 & 7.36 & 6.19 & 6.775 \\
\hline Jaunty & 5.98 & 3.98 & 4.35 & 4.9 & 4.625 \\
\hline Jealous & 6.14 & 6.92 & 3.26 & 5.2 & 4.23 \\
\hline Joyful & 4.55 & 2 & 6.58 & 6.2 & 6.39 \\
\hline Jubilant & 5.08 & 1.77 & 5.17 & 4.62 & 4.895 \\
\hline Jumpy & 7.22 & 6.37 & 3.54 & 4.41 & 3.975 \\
\hline Lonely & 5.78 & 7.17 & 3.85 & 5.14 & 4.495 \\
\hline Lyrical & 5.08 & 3.18 & 5.03 & 5.2 & 5.115 \\
\hline Melancholic & 4.42 & 5.76 & 4.16 & 4.23 & 4.195 \\
\hline Offended & 6.04 & 6.49 & 3.92 & 5.27 & 4.595 \\
\hline Panic & 8.26 & 7.78 & 2.8 & 3.36 & 3.08 \\
\hline Pardoning & 3.56 & 3.36 & 5.17 & 4.13 & 4.65 \\
\hline Passionate & 5.69 & 2.21 & 6.11 & 4.78 & 5.445 \\
\hline
\end{tabular}

(Continued)
Table 2 | Continued

\begin{tabular}{llllll}
\hline Emotion & Arousal & Valence & CF-self & CF-other & CF-overall \\
\hline Proud & 4.12 & 2.8 & 5.38 & 5.44 & 5.41 \\
Relaxed & 1.72 & 2.37 & 6.07 & 5.08 & 5.575 \\
Relieved & 2.68 & 2.45 & 5.38 & 5.02 & 5.2 \\
Remorseful & 5.29 & 5.53 & 3.33 & 3.35 & 3.34 \\
Sad & 5.91 & 6.6 & 4.51 & 5.48 & 4.995 \\
Shocked & 7.56 & 6.86 & 3.26 & 3.89 & 3.575 \\
Sick & 6.71 & 7.6 & 3.65 & 4.23 & 3.94 \\
Surprised & 5.74 & 4.09 & 4.73 & 5.14 & 4.935 \\
Triumphant & 5.5 & 3.48 & 3.77 & 4.09 & 3.93 \\
Troubled & 6.43 & 5.77 & 4.89 & 5.39 & 5.14 \\
Wistful & 5.47 & 6.03 & 3.52 & 3.74 & 3.63
\end{tabular}

The German translations were used in the actual questionnaire.

the dependent measure while the second one was computed for $\mathrm{CF}-$ other as the dependent measure. The first model, using CFself as the dependent measure, resulted in a significantly better fit compared to the null model $\left(\chi^{2}=168.07, \mathrm{df}=5, p<0.001\right)$. Furthermore, the only fixed effect with a significant effect on CFself was, just as for the previous models, valence $(-0.05 \pm 0.004$, $z=-11.63, p<0.001$ ). That is the more negative emotions were observed less often in one-self than positive emotions. There was no significant effect for age $(-0.001 \pm 0.001, z=-0.892$, $p=0.372)$, gender $(-0.02 \pm 0.028, z=-0.74, p=0.46)$, education level $(-0.011 \pm 0.013, z=-0.89, p=0.38)$, or arousal $(-0.0044 \pm 0.003, z=-1.317, p=0.19)$.

The second additional model with CF-other as the dependent measure resulted in a significantly better fit than the null model $\left(\chi^{2}=50.017, \mathrm{df}=5, p<0.001\right)$. As for the previous models, an increase in valence ratings, toward more negative values, was associated with a decrease in frequency $(-0.02 \pm 0.004$, $z=-3.854, p<0.001$ ) indicating that negative emotions were observed less often in others than positive emotions. The second fixed effect which had a significant influence on CF-other was age $(-0.003 \pm 0.001, z=-2.659, p<0.01)$ suggesting that an increase in age was associated with a decrease in the frequency of observing an emotion in others. There was no significant effect for gender $(0.029 \pm 0.029, z=1.01, p=0.31)$, education level $(0.023 \pm 0.014$, $z=1.67, p=0.095)$, or arousal $(0.005 \pm 0.003, z=1.48, p=0.14)$. A final model fitted to investigate the interaction effect of age and valence on CF-other did not reveal a significant interaction effect for the two fixed factors. The interaction effect of valence and frequency ratings for self and other are illustrated in Figure 1. In summary, for both CF-self and CF-other-ratings positive emotions were judged to be more frequent than negative emotions. However, very positive emotions were rated to be experienced more frequently in one-self than to be observed in others while very negative emotions were rated to be observed more often in others than experienced in one-self.

\section{VALENCE, AROUSAL, AND COMMUNICATIVE FREQUENCY AS SELECTION CRITERIA FOR A SET OF EMOTION WORDS}

We now demonstrate a concrete example of how communicative frequency can be used to arrive at a certain set of emotion words 


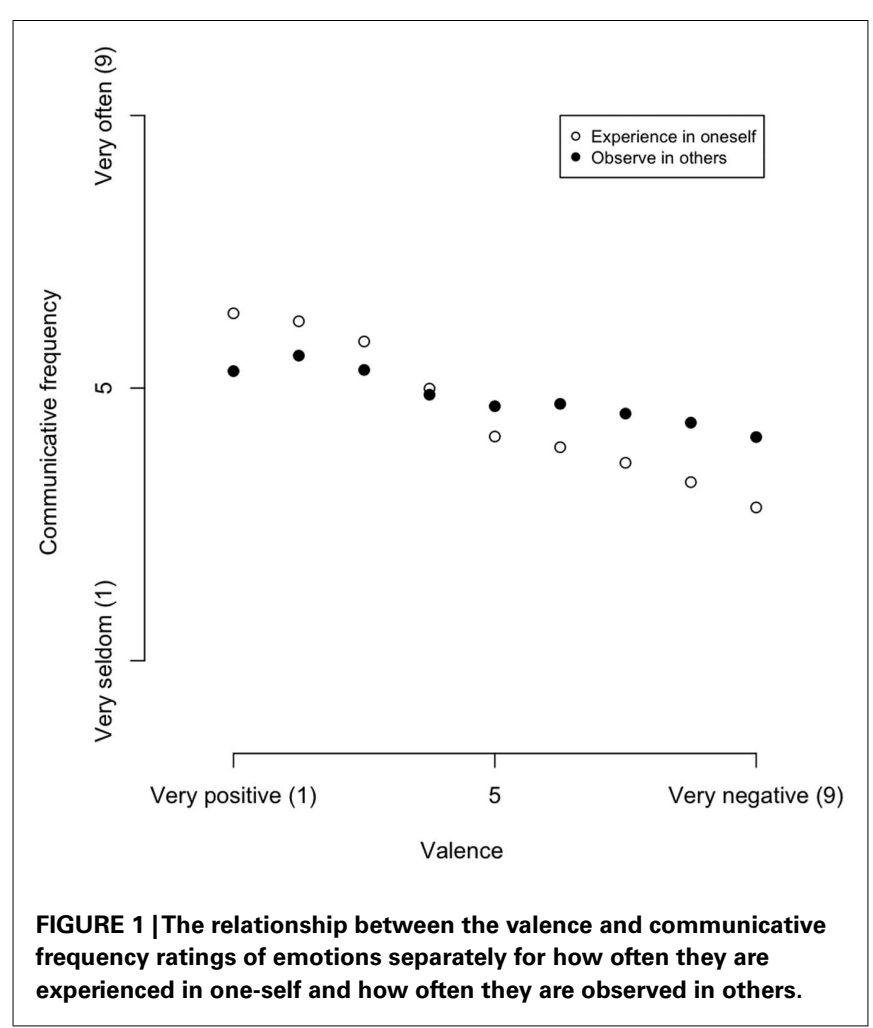

(40, in our example) complementing arousal and valence values. To arrive at an as accurate as possible estimate of the frequency with which an emotion occurs in everyday communication we collapsed across the two significantly correlated CF-self and CFother scores, $r$ Pearson $=0.42, p<0.001$, for each emotion (see also Tables 2 and 3 ). Thus, the overall communicative frequency rating, CF-overall, should provide a more parsimonious estimate of the actual frequency of occurrence than any one individual frequency rating by itself.

Given an initial emotion word list (in this case 62), we created four categories along arousal and valence: (1) high arousal/negative valence (HA/NV), (2) high arousal/positive valence (HA/PV), (3) low arousal/negative valence (LA/NV), and (4) low arousal/positive valence (LA/PV) using a cut-off value of $5(<5 \sim$ low, $>5 \sim$ high $)$. The distribution of the initial 62 emotion words consisted of 33 words with $\mathrm{HA} / \mathrm{NV}, 10$ words with HA/PV, 14 words with LA/PV, and 5 words with LA/NV. To make sure that the selected emotion words are representative of the initial 62 emotion words with respect to the distribution of the four categories, we kept the initial proportion of the four categories the same. For example, initially there were 33 highly arousing/negative valence emotion words within the 62 emotion words. With respect to a sample of 40 emotions the according number of highly arousing/negative emotion words was 20 . Therefore, the 20 emotion words with the highest overall frequency rating (CF-overall), which is the average of the CF-self and CFother scores, were included in that particular category. The final selection of 40 emotion words consisted of $20 \mathrm{HA} / \mathrm{NV}, 6 \mathrm{HA} / \mathrm{PV}$, $10 \mathrm{LA} / \mathrm{PV}$, and $4 \mathrm{LA} / \mathrm{NV}$ emotion words (see Table 4 ).

The mean ratings of the overall communicative frequency for each of the four word categories are displayed in Table 5.

\section{DISCUSSION}

In the present study, a total of 100 participants filled out a questionnaire that was designed to assess the valence and arousal levels of 62 emotion words. In addition, participants were asked to estimate two frequencies of occurrences, i.e., how often they experienced an emotion themselves (self-oriented) and how often they observed that emotion in others (other-oriented). The average of these two frequency estimates describes the frequency of emotions that occur in everyday human interactions. The results showed that positive emotions were generally judged to occur more frequently than negative emotions suggesting that there is a bias toward a greater frequency of occurrence of positive emotions in everyday life. On the one hand, the more negatively valenced emotions were rated to be observed more often in others than experienced in one-self while, on the other hand, more positively valenced emotions were experienced more often in one-self than they were observed in others. Finally, the higher the participants' age, the lower the frequency with which they observed emotions in other people. The communicative frequency of emotions may complement the dimensions of valence and arousal in determining the social relevance of emotions. This information can be valuable for researchers designing tools and interventions, which incorporate a selection of emotion words.

Firstly, the results of the conducted questionnaire replicated the "negativity bias" in the human affective lexicon (for a review, see Fredrickson, 1998). Negative emotion words were more numerous than positive emotion words. From an evolutionary perspective, a tendency to attend more strongly to negative stimuli rather than positive stimuli may have evolved to avoid harmful situations (Peeters and Czapinski, 1990). Hence, the adaptive significance of attending to negative stimuli may have led to the greater frequency of negative emotion words observed in the human affective lexicon.

Although negative emotion words are more numerous in the affective lexicon, our results suggest that they do not appear more frequently in everyday human interactions. We were not only interested in how often participants reported experiencing an emotion themselves, but wanted to assess additionally how frequently they reported observing these emotions in others. Thus, the current study's results extend the findings of a previous study by Scherer et al. (2004) in which reports of personal experience were used to estimate the probability of experiencing a given emotion in everyday life. By allowing participants to rate how often they experience an emotion themselves and how often they observe it in others, we arrived at a larger set of emotion words not restricted by participants' explicit recollection of past events. The scores from the two questions assessing self-oriented and other-oriented frequency of emotions were averaged to obtain a parsimonious estimate of the probability for encountering an emotion in a human interaction.

Despite the negativity bias in the written language, positive emotions were perceived to occur at a greater frequency than negative emotions. There appears to be a disparity between the negativity bias in the human affective lexicon and the increased frequency of experiencing and observing positive emotions in everyday communication. This may suggest that the display of negative emotions is regarded as less socially desirable. Intuitively, humans feel more inclined to keep negative feelings and thoughts private 
Table 3 | Emotions ranked by arousal, valence, and overall communicative frequency with respective values.

\begin{tabular}{|c|c|c|c|c|c|}
\hline \multicolumn{2}{|l|}{ Ranked by arousal } & \multicolumn{2}{|c|}{ Ranked by valence } & \multicolumn{2}{|c|}{ Ranked by overall communicative frequency } \\
\hline Frantic & 8.41 & Hateful & 8.27 & Interested & 6.775 \\
\hline Panic & 8.26 & Panic & 7.78 & Curious & 6.49 \\
\hline Aggressive & 8.12 & Sick & 7.6 & Joyful & 6.39 \\
\hline Angry & 8.06 & Desperate & 7.53 & Amused & 6.245 \\
\hline Desperate & 7.48 & Angry & 7.5 & Caring & 6.005 \\
\hline Jumpy & 7.22 & Frustrated & 7.46 & Content & 5.955 \\
\hline Aghast & 7.2 & Disgusted & 7.42 & Grateful & 5.875 \\
\hline Anxious & 7.04 & Frantic & 7.41 & Expectant & 5.685 \\
\hline Agonized & 6.99 & Lonely & 7.17 & Cross & 5.665 \\
\hline Guilty & 6.59 & Envious & 6.75 & Proud & 5.41 \\
\hline Contemptuous & 6.46 & Disappointed & 6.73 & Relieved & 5.2 \\
\hline Troubled & 6.43 & Cross & 6.68 & Doubtful & 5.15 \\
\hline Confused & 6.29 & Hurt & 6.64 & Troubled & 5.14 \\
\hline Concerned & 6.27 & Sad & 6.6 & Lyrical & 5.115 \\
\hline In love & 6.27 & Anxious & 6.59 & Aggressive & 5.08 \\
\hline Grievous & 6.26 & Offended & 6.49 & Sad & 4.995 \\
\hline Hurt & 6.26 & Aghast & 6.47 & Disappointed & 4.99 \\
\hline Jealous & 6.14 & Jumpy & 6.37 & Angry & 4.98 \\
\hline Doubtful & 6.05 & Doubtful & 6.25 & Enthusiastic & 4.98 \\
\hline Surprised & 5.74 & Aggrieved & 5.65 & Offended & 4.595 \\
\hline Enthusiastic & 5.73 & Concerned & 5.6 & Bored & 4.545 \\
\hline Passionate & 5.69 & Remorseful & 5.53 & Lonely & 4.495 \\
\hline Triumphant & 5.5 & Compassionate & 5.47 & Envious & 4.49 \\
\hline Wistful & 5.47 & Embarrassed & 5.04 & Embarrassed & 4.46 \\
\hline Expectant & 5.37 & Apologetic & 4.84 & Compassionate & 4.45 \\
\hline Remorseful & 5.29 & Surprised & 4.09 & Apologetic & 4.38 \\
\hline Jubilant & 5.08 & Jaunty & 3.98 & Hurt & 4.32 \\
\hline Lyrical & 5.08 & Expectant & 3.57 & Grievous & 4.29 \\
\hline Curious & 5.01 & Triumphant & 3.48 & Jealous & 4.23 \\
\hline Embarrassed & 4.96 & Pardoning & 3.36 & Melancholic & 4.195 \\
\hline Humble & 4.96 & Curious & 3.34 & Aghast & 4.07 \\
\hline Compassionate & 4.95 & Lyrical & 3.18 & Jumpy & 3.975 \\
\hline Apologetic & 4.73 & Caring & 3.06 & Confused & 3.975 \\
\hline Joyful & 4.55 & Proud & 2.8 & Sick & 3.94 \\
\hline Melancholic & 4.42 & Enthusiastic & 2.66 & Triumphant & 3.93 \\
\hline Proud & 4.12 & Confident & 2.61 & Desperate & 3.85 \\
\hline Bored & 4.04 & Affectionate & 2.57 & Ashamed & 3.68 \\
\hline Interested & 3.96 & Interested & 2.54 & Wistful & 3.63 \\
\hline Caring & 3.65 & Grateful & 2.52 & Disgusted & 3.615 \\
\hline
\end{tabular}


Table 3 | Continued

\begin{tabular}{|c|c|c|c|c|c|}
\hline \multicolumn{2}{|c|}{ Ranked by arousal } & \multicolumn{2}{|c|}{ Ranked by valence } & \multicolumn{2}{|c|}{ Ranked by overall communicative frequency } \\
\hline Pardoning & 3.56 & Amused & 2.47 & Shocked & 3.575 \\
\hline Amused & 3.45 & Relieved & 2.45 & Guilty & 3.445 \\
\hline Carefree & 3.4 & Relaxed & 2.37 & Frantic & 3.385 \\
\hline Grateful & 3 & Carefree & 2.34 & Humble & 3.365 \\
\hline Affectionate & 2.9 & Content & 2.28 & Remorseful & 3.34 \\
\hline Confident & 2.7 & Passionate & 2.21 & Contemptuous & 3.125 \\
\hline Relieved & 2.68 & Joyful & 2 & Panic & 3.08 \\
\hline Content & 2.05 & Jubilant & 1.77 & Hateful & 2.935 \\
\hline Relaxed & 1.72 & In love & 1.72 & Agonized & 2.815 \\
\hline
\end{tabular}

The German translations were used in the actual questionnaire.

Table 4 | A selection of 40 emotion words based on the result of the questionnaire analysis listing the most frequent emotions (average of CF-self and CF-other) within each category.

\begin{tabular}{|c|c|c|}
\hline & High arousal & Low arousal \\
\hline & Contemptuous (3.13) & Melancholic (4.2) \\
\hline & Guilty (3.45) & Compassionate (4.45) \\
\hline & Disgusted (3.62) & Embarrassed (4.46) \\
\hline & Wistful (3.63) & Bored (4.55) \\
\hline & Desperate (3.85) & \\
\hline & Confused (3.98) & \\
\hline & Aghast (4.07) & \\
\hline & Envious (4.23) & \\
\hline \multirow[t]{15}{*}{ Negative valence } & Aggrieved (4.32) & \\
\hline & Jealous (4.49) & \\
\hline & Offended (4.595) & \\
\hline & Anxious (4.635) & \\
\hline & Frustrated (4.805) & \\
\hline & Concerned (4.95) & \\
\hline & Angry (4.98) & \\
\hline & Disappointed (4.99) & \\
\hline & Sad (5) & \\
\hline & Troubled (5.14) & \\
\hline & Doubtful (5.15) & \\
\hline & Cross (5.57) & \\
\hline & Surprised (4.94) & Apologetic (4.38) \\
\hline & Enthusiastic (4.98) & Pardoning (4.65) \\
\hline & Lyrical (5.12) & Relieved (5.2) \\
\hline \multirow[t]{7}{*}{ Positive valence } & In love (5.5) & Proud (5.41) \\
\hline & Expectant (5.69) & Grateful (5.875) \\
\hline & Curious (6.49) & Content (5.955) \\
\hline & & Confident (6.04) \\
\hline & & Amused (6.25) \\
\hline & & Joyful (6.48) \\
\hline & & Interested (6.78) \\
\hline
\end{tabular}

The most frequent word is listed first. The German translations were used in the actual questionnaire.

(Sommers, 1984) and to limit the expression of negative emotions to a small group of people, such as family and closer friends. In addition, Harker and Keltner (2001) found that individuals who
Table 5 |The mean communicative frequency rating (average of CF-self and CF-other) within the four categories.

\begin{tabular}{lll}
\hline & High arousal & Low arousal \\
\hline Negative valence & $M=4.43(\mathrm{SD}=0.68)$ & $M=4.41(\mathrm{SD}=0.15)$ \\
Positive valence & $M=5.45(\mathrm{SD}=0.59)$ & $M=5.7(\mathrm{SD}=0.78)$ \\
\hline
\end{tabular}

$M$, mean; $S D$, standard deviation.

express positive emotions are rated more favorably on a number of personality traits and are perceived as more desirable partners for potential social interaction. Indeed, previous research has suggested that positive affect promotes desirable life outcomes in several domains, including friendship, health, income, and career success (Harker and Keltner, 2001; Lyubomirsky et al., 2005; Boehm and Lyubomirsky, 2008).

Further explanations for the frequency differences of positive vs. negative emotion words in the affective lexicon vs. everyday communication might stem from the fact that humans are highly social animals. The presentation of positive affect may provide a better foundation for intact social relationships. Thus, the high occurrence of positive emotions could reflect a strong propensity to maintain social bonds. In addition, fewer events occur in everyday human interactions that elicit high arousing negative emotions making negative emotions less frequent. However, positive emotions are not short-lived but rather endure. To summarize, it is possible that negative emotions are less frequent in everyday human communication even though they are highly relevant for human survival. In contrast, positive emotions occur more frequently to facilitate human interactions, which is a hypothesis that could be tested in future studies.

It is interesting to speculate about the absence of any effect of arousal ratings on the ratings of communicative frequency. This finding is somewhat surprising since one may expect that highly arousing emotions - i.e., those that are felt most intensely - should be less frequent in every day communication. One explanation might be that people can be expected to avoid highly arousing negative emotions whereas the experience of intense positive emotions is likely to be more difficult to attain. Likewise, people might habituate to initially intensely felt emotions and subsequently judge them to be less arousing (as they occur more often in life). Furthermore, our results also suggest that it is not the case that less 
arousing emotions are more numerous than high arousing emotions. One may speculate that the absence of an effect of arousal on communicative frequency is due to the possibility that less arousing feelings are not as readily registered and therefore do not make it into conscious awareness - resulting in similar ratings of high an low arousing emotions. These potential explanations may provide interesting questions for future research.

An important aspect that needs to be considered is that participants' responses may have been influenced by a bias toward positive self-reports (Taylor and Brown, 1988). On this note, participants may have reported experiencing positive emotions more often than negative emotions because they were concerned about preserving a positive self-image. In addition, people are generally likely to avoid leaving a negative impression on others, which could also have influenced their ratings. This notion corresponds to evidence indicating that a person's emotional displays can have important interpersonal consequences with others being more attracted to happy, and more avoidant toward sad people in a variety of contexts (Frijda and Mesquita, 1994; Keltner and Kring, 1998). Indeed, it has recently been suggested that attracting others by means of positive emotions may have had important fitness implications in human evolution as people who maintain positive emotional dispositions are more effective in their goal pursuits (von Hippel and Trivers, 2011). Correspondingly, our results show that very positive (valence ratings of less than 4) emotions were rated to be experienced more often in one-self than to be observed in others, while very negative emotions (valence ratings exceeding 5) were rated to be observed more often in others than experienced in one-self. For the purpose of selecting a set of emotion words for social cognition training tools, we suggested to use the average of both the self- and other-measure taking into account the confounds regarding concerns about self-image and negative impression. Thereby, potential biases in participants' responses are balanced out, thus providing a more parsimonious estimate of an emotion's communicative frequency in everyday life. Therefore, assessing the occurrence of emotions based on two perspectives of self- and other-ratings allowed us to capture the phenomenon that positive as opposed to negative emotions are more numerous in everyday interactions.

An additional important point to make is that the measure of an emotion's communicative frequency is not an assessment of the emotion's significance. In fact, an individual's increased exposure to an emotion may reduce its significance (Siddle, 1991; Wright et al., 2001), e.g., phobia patients are treated through repeated exposure to an initially fear-evoking situation. Furthermore, humans develop to attend more readily to negative emotions, possibly because of their significance in behavior adjustment (Vaish et al., 2008). Moreover, the question of whether, among negative emotions, the least frequent are the most important is beyond the scope of the current paper but an interesting question to follow up on in future studies. In addition, it is possible that the psychological well-being of participants may have influenced their ratings. Participants registered in our database have stated that they did not have any psychological or neurological history prior to study onset. Furthermore, we provided participants with as much time as they needed to fill out the questionnaire.
It has to be acknowledged that our study was carried out in one particular cultural context, i.e., in Germany. While it can be assumed that Germany shares several cultural practices with other western individualistic cultures (such as other western European countries or the USA), it has been pointed out that the cultural practices of emotions, their social functions and connotations can vary, even within Western cultures (Averill, 2004; see Härtel and Härtel, 2005, for a review). Future research could address the issue of communicative frequency and the identification of communicatively frequent emotions in different cultures. This may be particularly important considering potential clinical significance of a representative sample of emotion words for the development of training and diagnostic tools.

Finally, we wanted to show how the information about the frequency of occurrence of emotions can guide researchers to select samples of emotion words when designing clinical tests or socio-emotional intervention tools. A selection of emotion words with respect to valence, arousal, and communicative frequency may potentially be used in tools to enhance treatment efficacy by implementing highly relevant emotion words for everyday communication. Such a differentiated approach to selecting emotions complements recent findings documenting a developmental pattern of the occurrence of various emotion words across childhood (Baron-Cohen et al., 2010). The concept of assessing the frequency, at which an emotion occurs does not question previous taxonomies, but rather extends them by providing information based on an additional dimension (frequency). For example, this additional dimension can be applied as a criterion to restrict the number of emotion words when designing a tool in order to yield a manageable but relevant selection to everyday human communication.

In sum, the present study provides empirical data showing that positive emotions are experienced and observed more often than negative emotions in human everyday communication in a sample of German participants. These results complement ratings along the rather classic emotion dimensions, valence, and arousal, in further defining the communicative frequency of emotion words. Future studies are needed to validate this finding in other languages (e.g., English) within the same and different cultural circumstances. We additionally show exemplarily how those frequency ratings as a measure of communicative relevance can be utilized to arrive at a manageable set of emotion words for socio-emotional tools. One way to ascertain whether our selection of emotions is useful would be to use them in a social cognition training tool, an endeavor that is currently underway in our laboratory. The success of this intervention in a clinical population will serve as the first benchmark for the efficiency of the presented emotion selection supporting the utility of selecting a subpopulation of emotions from a larger taxonomy.

\section{ACKNOWLEDGMENTS}

This work was supported by the Max Planck Society and the German Research Foundation (Cluster of Excellence "Language of Emotion," EXC 302). We would like to thank Roger Mundry for his advice on statistics. 


\section{REFERENCES}

American Psychiatric Association. (1994). Diagnostic and Statistical Manual of Mental Disorders, 4th Edn. Washington, DC: American Psychiatric Association.

Averill, J. (2004). Everyday emotions: let me count the ways. Soc. Sci. Info. 43, 571-580.

Averill, J. R. (1980). "On the paucity of positive emotions," in Advances in the Study of Communication and Affect, Vol. 6, Assessment and Modification of Emotional Behavior, eds K. R. Blankstein, P. Pliner, and J. Polivy (New York: Plenum), $7-45$.

Baayen, R. H. (2008). Analyzing Linguistic Data. Cambridge: Cambridge University Press.

Baron-Cohen, S. (1995). Mindblindness: An Essay on Autism and Theory of Mind. Boston, MA: MIT Press.

Baron-Cohen, S., Golan, O., Chapman, E., and Granader, Y. (2007). Transported to a world of emotions. Psychologist 20, 76-77.

Baron-Cohen, S., Golan, O., Wheelwright, S., Granader, Y., and Hill, J. (2010). Emotion word comprehension from 4 to 16 years old: a developmental survey. Front. Evol. Neurosci. 2:109. doi:10.3389/fnevo.2010.00109

Baron-Cohen, S., Golan, O., Wheelwright, S., and Hill, J. (2004). Mind Reading: The Interactive Guide to Emotions. London: Jessica Kingsley Limited.

Baron-Cohen, S., Wheelwright, S., Hill, J., Raste, Y., and Plumb, I. (2001). The "reading the mind in the eyes" test revised version: a study with normal adults, and adults with Asperger syndrome or high-functioning autism. J. Child Psychol. Psychiatry 42, 241-251.

Bates, D., and Maechler, M. (2009). lme4: linear mixed-effects models using S4 classes. R package version 0.999375-31. http://CRAN.Rproject.org/package $=$ lme 4

Ben-Ze'ev, A. (1997). The affective realm. New Ideas Psychol. 15, 247-259.

Biemann, C., Bordag, S., Heyer, G., Quasthoff, U., and Wolff, C. (2004). "Language-independent methods for compiling monolingual lexical data," in Proceedings of CicLING, Seoul, 215-228.

Boehm, J. K., and Lyubomirsky, S. (2008). Does happiness promote career success? J. Career Assess. 16, 101-116.

Bölte, S., Feineis-Matthews, S., Leber, S., Dierks, T., Hubl, D., and Poustka, F. (2002). The development and evaluation of a computer-based program to test and teach the recognition of facial affect. Int. J. Circumpolar Health 61, 61-68.

Bradley, M. M., and Lang, P. J. (1994). Measuring emotion: the selfassessment manikin and the semantic differential. J. Behav. Ther. Exp. Psychiatry 25, 49-59.

Clore, G. L., Ortony, A., and Foss, M. A. (1987). The psychological foundation of the affective lexicon. J. Pers. Soc. Psychol. 53, 751-766.

Cohn, M. A., Fredrickson, B. L., Brown, S. L., Mikels, J. A., and Conway, A. M. (2009). Happiness unpacked: positive emotions increase life satisfaction by building resilience. Emotion 9, 361-368.

Darwin, C. (2004). The Descent of Man, and Selection in Relation to Sex. London: Penguin Books.

de Haan, M., Belsky, J., Reid, V., Volein, A., and Johnson, M. H. (2004). Maternal personality and infants' neural and visual responsivity to facial expressions of emotion. J. Child Psychol. Psychiatry 45, 1209-1218.

Dunn, J. (1988). The Beginnings of Social Understanding, 1st Edn. Cambridge, MA: Harvard University Press.

Dziobek, I., Fleck, S., Kalbe, E., Kimberly, R., Hassenstab, J., Brand, M., Kessler, J., Woike, J. K., Wolf, O. T., and Convit, A. (2006). Introducing MASC: a movie for the assessment of social cognition. J. Autism Dev. Disord. 36, 623-636.

Fontaine, J. R., Scherer, K. R., Roesch, E. B., and Ellsworth, P. (2007). The world of emotion is not two-dimensional. Psychol. Sci. 18, 1050-1057.

Fredrickson, B. L. (1998). What good are positive emotions? Rev. Gen. Psychol. 2, 300-319.

Frijda, N. H., and Mesquita, B. (1994). "The social roles and functions of emotions," in Emotion and Culture: Empirical Studies of Mutual Influence, eds S. Kitayama and H. R. Markus, Washington, DC: American Psychological Association, 51-87.

Goetz, J. L., Keltner, D., and SimonThomas, E. (2010). Compassion: an evolutionary analysis and empirical review. Psychol. Bull. 136, 351-374.

Harker, L., and Keltner, D. (2001). Expressions of positive emotion in women's college yearbook pictures and their relationship to personality and life outcomes across adulthood. J. Pers. Soc. Psychol. 80, 112-124.

Härtel, C. E. J., and Härtel, G. F. (2005). Cross-cultural differences in emotions: the why and how. Soc. Sci. Info. 44, 683-693.

Hobson, P. R., Ouston, J., and Lee, A. (1988). Emotion recognition in autism: coordinating faces and voices. Psychol. Med. 18, 911-923.

Keltner, D. (2009). Born to be Good: The Science of a Meaningful Life. New York, NY: Norton.

Keltner, D., and Kring, A. (1998). Emotion, social function, and psychopathology. Rev. Gen. Psychol. 2, 320-342.

Likert, R. (1932). A technique for the measurement of attitudes. Arch. Psychol. 22, 1-55.

Lyubomirsky, S., King, L., and Diener, E. (2005). The benefits of frequent positive affect: does happiness lead to success? Psychol. Bull. 131, 803-855.

Montag, C., Dziobek, I., Richter, I. S. Neuhaus, K., Lehmann, A., Rudolf, S., Heekeren, H. R., Heinz, A., and Gallinat, J. (2011). Different aspects of theory of mind in paranoid schizophrenia: evidence from a videobased assessment. Psychiatry Res. 186, 203-209.

Morgan, R. L., and Heise, D. (1988) Structure of emotions. Soc. Psychol. Q. 51, 19-31.

Peeters, G., and Czapinski, J. (1990). Positive-negative asymmetry in evaluations: the distinction between affective and informational negativity effects. Eur. Rev. Soc. Psychol. 1, 33-60.

Preißler, S., Dziobek, I., Ritter, K., Heekeren, H. R., and Roepke, S. (2010). Social cognition in borderline personality disorder: evidence for disturbed recognition of the emotions, thoughts, and intentions of others. Front. Behav. Neurosci. 4:182. doi:10.3389/fnbeh.2010.00182

R Development Core Team. (2009). R: A Language and Environment for Statistical Computing. Vienna: R Foundation for Statistical Computing.

Ritter, K., Dziobek, I., Preißler, S. Rüter, A., Vater, A., Fydrich, T., Lammers, C.-H., Heekeren, H. R., and Roepke, S. (2011). Lack of empathy in patients with narcissistic personality disorder. Psychiatry Res. 187, 241-247.

Rosenberg, E. L. (1998). Levels of analysis and the organization of affect. Rev. Gen. Psychol. 2, 247-270.

Russell, J. A. (1980). A circumplex model of affect. J. Pers. Soc. Psychol. 39, 1161-1178.

Russell, J. A., and Barrett, L. F. (1999) Core affect, prototypical emotional episodes, and the other thing called emotion: dissecting the elephant. J. Pers. Soc. Psychol. 76, 805-819.

Scherer, K. R., Wranik, T., Sangsue, J., Tran, V., and Scherer, U. (2004). Emotions in everyday life: probability of occurrence, risk factors, appraisal and reaction patterns. Soc. Sci. Info. 43, 499-570.
Shaver, P., Schwartz, J., Kirson, D., and O'Connor, C. (1987). Emotion knowledge: further exploration of a prototype approach. J. Pers. Soc. Psychol. 52, 1061-1086.

Siddle, D. A. (1991). Orienting, habituation, and resource allocation: an associative analysis. Psychophysiology 28, 245-259.

Sommers, S. (1984). Reported emotions and conventions of emotionality among college students. J. Pers. Soc. Psychol. 46, 207-215.

Storm, C., and Storm, T. (1987). A taxonomic study of the vocabulary of emotions. J. Pers. Soc. Psychol. 53, 805-816.

Taylor, S. E., and Brown, J. D. (1988). Illusion and well-being: a social psychological perspective on mental health. Psychol. Bull. 103, 193-210.

Vaish, A., Grossmann, T., and Woodward, A. (2008). Not all emotions are created equal: the negativity bias in social-emotional development. Psychol. Bull. 134, 383-403.

von Hippel, W., and Trivers, R. (2011). The evolution and psychology of self-deception. Behav. Brain Sci. 34, $1-56$.

Wright, C. I., Fischer, H., Whalen, P. J., McInerney, S. C., Shin, L. M. and Rauch, S. L. (2001). Differential prefrontal cortex and amygdala habituation to repeatedly presented emotional stimuli. Neuroreport 12, 379-383.

Conflict of Interest Statement: The authors declare that the research was conducted in the absence of any commercial or financial relationships that could be construed as a potential conflict of interest.

Received: 20 April 2011; accepted: 26 September 2011; published online: 18 October 2011.

Citation: Hepach $R$, Kliemann D, Grüneisen S, Heekeren HR and Dziobek I (2011) Conceptualizing emotions along the dimensions of valence, arousal, and communicative frequency - implications for social-cognitive tests and training tools. Front. Psychology 2:266. doi: 10.3389/fpsyg.2011.00266

This article was submitted to Frontiers in Emotion Science, a specialty of Frontiers in Psychology.

Copyright (c) 2011 Hepach, Kliemann, Grüneisen, Heekeren and Dziobek. This is an open-access article subject to a nonexclusive license between the authors and Frontiers Media SA, which permits use, distribution and reproduction in other forums, provided the original authors and source are credited and other Frontiers conditions are complied with. 